\title{
LA NOVELA DE LOS MERCADERES
}

\section{Guillermo Alberto Arévalo*}

\begin{abstract}
Es obvio que una cosa es la humanidad y otra muy distinta el público-masa, ese conjunto de seres que han dejado de ser hombres para convertirse en objetos fabricados en serie, moldeados por una educación estandarizada, embutidos en fábricas y oficinas, sacudidos diariamente al unísono por las noticias lanzadas por centrales electrónicas, pervertidos y cosificados por una manufactura de historietas y novelones de cromos periodísticos y de estatuillas de bazar.
\end{abstract}

El tema de la participación de los escritores en la televisión se ha convertido, desde hace unos años, en frecuente tópico de conversaciones, entrevistas, críticas y especulaciones, tanto entre los aficionados al comentario farandulero como en los medios académicos. Si bien en la mayoría de los casos se ha dado prioridad a las exculpaciones de los implicados, no faltan los elementos que dan pie a una polémica que, pensamos, resulta útil para la precisión de conceptos acerca del oficio literario que hoy por hoy circulan con alegría a través de periódicos y revistas de la más diversa índole.

El debate, en apariencia, suena a cosa local. Con todo, al observar la cada vez más frecuente incursión en él de escritores, cineastas, actores de todas las latitudes, adquiere un carácter mucho más amplio, tanto geográfica como culturalmente. Basta repasar un par de as ertos de autoridades del "medio" (como dicen los teóricos), para cons tatarlo. Un primer ejemplo es el de Federico Fellini en una entrevista para Time: opina el director italiano que (la televisión) "paulatinamente nos corrom pe el gus to".

El producto final es una especie de batiburillo en que la violencia de los actos de terrorismo, los cortes para comerciales, el semón de los predicadores, las películas viejas y la lección acerca de cómo cortar en tajadas el salami, constituyen un espectáculo de tal manera baladí, que quedamos exhaustos y con una sensación de vacío. Deberíamos poder renunciar a ella, limitarnos a dos canales por país, o inclusive a dos días a la semana (...) La pantalla chica confunde los sentidos ${ }^{2}$.

\footnotetext{
*Profesor de Literatura. Universidad Pedagógica Nacional.

${ }_{1}^{1}$ Sábato, Ernesto. El escritor y sus fantasmas. Buenos Aires: Emecé, 1979, p. 35.

2 Fel lini, Federico. "La TV corrompe el gusto". Lecturas Dominicales de El Tiempo. Bogotá, febrero 16 de 1986, p.3
} 
Eliminemos de entrada el socorrido argumento de un desconocimiento del medio". Me apoyo en conocedores de vieja data e indisputada autoridad, como Fellini, o como Jean-Luc Godard, para quien la televisión "no crea, porque está llena de funcionarios", y además sólo ha resuelto "el problema de la difusión", y eso porque "está en las casas de los espectadores", pero:

Satisface la necesidad de cultura, la cultura entendida como agricultura, como necesidad de consumo. La Tele, al dar cultura, satisface una necesidad. El arte (...) responde a un deseo. La televisión fabrica olvido. El cine, la pintura, las novelas, son gitanos. La televisión no es cosa de nómadas $^{3}$

Y no solamente se refieren al problema directores de cine. Escogiendo apenas una de entre las opiniones de los novelistas contemporáneos, la siguiente, de Milán Kundera, es ilus trativa:

Si la novela titubea (en los países occidentales), es porque se sitúa en un mundo que no es el suyo. Sus valores (...) se encuentran en contradicción con la unifomación, con el espíritu de los medios de comunicación y con el carácter kitsch de nuestra época 4 .

Naturalmente, al medio le brotan defensores. Es el lamentable caso de "nuestro" Premio Nóbel, quien, en reportaje para Diario 16 de España, decidió que "la palabra escrita es un medio muy primitivo", que "es casi como la escritura cuneiforme", y que, en cambio, la imagen "con un solo impacto te produce una impresión inmediata”. Agregó García Márquez:

Yo siem pre he querido escribir telenovelas. Es una maravilla, Llega a muchas más personas que un libro (...). Es mucho más eficaz una telenovela que una novela ${ }^{5}$.

Como a los boxeadores habría que recomendar a ciertos escritores que se retiren a tiempo, al menos del cuadrilátero de las entrevistas de prensa.

Esto motiva, cuando menos, una reflexión acerca del medio de difusión escogido por un grupo de escritores colombianos en los años recientes para dar a conocer sus obras, generando lo que algún articulista denominó como "nuevo boom" de la narrativa colombiana.

\footnotetext{
${ }^{3}$ Godard, Jean-Luc. "El cine, la pintura, las novelas son gitanos. La televisión no es cosa de nómadas' El Mundo Semanal. Medellín, enero 23 de 1988 p.3 (Tomada de Diario 16).

${ }^{4}$ Kundera, Milan. "Agonía de la novela" (Reseña de José Hernández sobre El arte de la novela ). Lecturas Dominicales de El Tiempo. Bogotá, febrero 22 de 1987, p.4.

5 Véase el artículo "El boom en perspectiva" de Angel Rama, en la recopilación La novela latinoamericana1920-1 980. Bogotá, Procultura-Colcultura, 1982 pp. 235 - 293.
} 


\section{Explosión del mercado}

La palabra boom no es nueva en el lenguaje referente a la literatura latinoamericana. Sobre su significación surgieron múltiples versiones, si bien la mayoría aludió más a un fenómeno comercial que a una realidad literaria. Aquella explosión cobijó a un grupo de narradores que abrió el camino para el conocimiento universal de una literatura, la de América Latina, que hasta entonces, salvo contadas excepciones, no tras cendía las fronteras parroquiales. Al mismo tiempo constituyó una fuente de enriquecimiento para algunas editoriales y para los escritores que supieron aprovechar la coyuntura. Sin embargo, la gran mayoría de estos se caracterizó por la producción de obras de mucha exigencia, producto de una formación rigurosa, escritas muchas veces en medio de sacrificios materiales y concebidas bajo la vigilancia de una autocrítica que nos resultaba desconocida.

Los rasgos de los libros del "nuevo boom" de la novelística colombiana, lamentablemente, no coinciden con los de aquella época, no obstante honrosas excepciones. Entre "lo que vende", la calidad de la escritura pareciera "pasada de moda"; el afán notorio se centra en el logro económico. Como si García Márquez fuera un ejem plo por haber vendido tal o cual de sus más recientes novelas a un determinado precio, y no por haber resistido, en sus años de soledad, todas las presiones de un medio cultural tradicionalista y hostil, hasta ganar el lugar que corres pondía a su esfuerzo y a su disciplina.

Hoy se ha impuesto el poder de la propaganda, la máxima venta de ejem plares, la promoción de la 'imagen' del autor. Y el vehículo soñado para tan frívolo propósito es la televisión.

El éxito editorial, en efecto, se ve condicionado a la adopción televisiva de una novela: "Qué bueno leerla antes de haberla visto", se dice acerca de los actuales "impactos" narrativos. En la presentación de un muy novedoso autor del género, se llegó al paroxismo:

Ese jueves 24 de septiembre recibió una llamada. Los directivos de Caracol Televisión querían llevar a la pantalla su obra Caballo Viejo.

José Luís Garcés comprendió que algún dios de la literatura zenú le abrió el campo. Se lo agradeció, pues interiomente sabe que después de 20 años dedicados a las letras es justo que llegue el día del reconocimiento y, de paso, la gloria ${ }^{6}$.

\footnotetext{
${ }^{6}$ Martínez Xiomara: "Cuando la fama llega así no se da ni cuenta" (Entrevista con José Luis Garcés) Bogotá. El Tiempo, febrero 10 de 1988. p. 5-C
} 
Los ejemplos previos han inducido la convicción, entre los escritores jóvenes, de que el éxito de librerías equivale a la consagración artística. La experiencia de siglos enseña que lo uno no tiene nada que ver con lo otro.

Para citar un solo ejemplo, David Sánchez Juliao, pionero del negocio, contes tó a fundadas críticas de carácter literario sobre Pero sigo siendo el rey con las siguientes palabras:

A nivel internacional, mi libro es considerado como uno de los mejores (...) La novela va en su segunda edición y se han vendido 40.00 ejemplares, cuando la mayoría de escritores no pasan de editar 1.000 copias y regalarlas entre los amigos ${ }^{7}$.

En otra entrevista, su Sosia, Gustavo Alvarez G., echó más luz sobre el fenómeno:

Cuando salió El Rey, que era Premio Plaza y Janés, su venta fue equis. Salió la telenovela, y su venta fue tres equis ${ }^{8}$.

Se torna evidente que el objetivo no es escribir, vi vir para el arte, crear, sino ganar dinero con la literatura, vender más, promover la imagen. Como medio de difusión, en el marco social y económico colombiano, la televisión presenta una idiosincracia definida; quienes más contactos tienen con ella lo reconocen a menudo; el director Jorge Alí Triana, verbigracia, cuando concede que:

Los estudios de sintonía indican qué ve y qué quiere ver la gente. Son estudios enmarcados en un populismo burdo. (...) La sintonía es inversamente proporcional a la calidad y al contenido. (...) El objetivo de las programadoras no es dar cultura $y$ recreación. No es cumplir una tarea social. Esto es un negocio?.

Cabría recordarles a los comerciantes de la cultura la consideración del narrador y ensayista unuguayo Eduardo Galeano:

No siempre los datos de tiraje o venta dan la medida de la resonancia de un libro. A veces la obra escrita irradia una influencia mucho mayor que su difusión aparente; a veces responde con años de anticipación a las preguntas y necesidades colectivas, si el creador ha sabido vivirla previamente como dudas y desgarramientos dentro de sí. La obra brota de la conciencia

\footnotetext{
${ }^{7}$ Sánchez Juliao, David en Semana. Bogotá, No. 99, marzo 27 abril 7 de 1987, p. 48.

${ }^{8}$ Alvarez Gardeazábal, Gustavo, "Novelistas y telenovelas" (Mesa redonda en compañía con David Sánchez J) Bogotá, Pluma No. 58, jun-jul de 1987. pp. 6-16. En adelante todas las referencias a Pluma se referirán a esta entrevista.

${ }^{9}$ Duzán, María Jimena, Marisol Cano y Guillemo González. "No tocar œnflictos en TV implicaría hacer un surrealismo de jabón" (Entrevista a Jorge Alí Triana) El Espectador, Bogotá, octubre 4 de 1987 p. 10 A.
} 
herida del escritor y se proyecta al mundo; el acto de creación es un acto de solidaridad que no siempre cumple su destino en vida de quien lo realiza ${ }^{10}$.

De la tiranía de los "ratings" o encuestas de sintonía, no se han librado siquiera los gobemantes del país. Invariablemente, las campañas electorales incluyen la promesa de "dar gusto al público" en cuanto a la programación, pasando por encima de cualquier otro criterio, sea este artístico, cultural o ético. Ello configura un grave cuadro. Pues incluso un popular periodista del propio medio, Rodrigo Beltrán, confimó, cuando le preguntaron sobre los defectos de la televisión colombiana, que el mayor es:

El acelerado objetivo de comercialización sin tener en cuenta el valor profesional de un director, de un libretista o de un actor, y mucho menos de los televidentes. Es un mercado cuyo único objetivo es vender, en donde priman las encuestas que miden el aspecto cuantitativo de los programas, pero nunca la calidad ${ }^{11}$.

Significativamente, la más promocionada de las adaptadoras de novelas colombianas para la televisión, doña Martha Bossio de Martínez, tituló un comentario para la revista Semana, al comparar dos telenovelas extranjeras enfrentadas en su horario, con una confesión: “¿Quién ganará? ¡La NIELSEN dirá! Aludía a una de las más conocidas empresas dedicadas a encuestas periódicas de sintonía.

\section{"El que peca y reza..."}

Dejemos sentado, de una vez, que no consideramos ilícita para un escritor la vinculación a la TV, ni al periodismo, ni a la radio, ni al video, ni al cine. Sin embargo, en tal evento existen dos posibilidades: o se sacrifica el arte a la ganancia económica, o se logra imponer criterios que mantengan intacta la dignidad de la literatura y, de paso, se eleva el nivel (por cierto, deplorable) del medio escogido;

Por lo que hace a las declaraciones que conozco, la mas sincera al respecto proviene de Manuel Mejía Vallejo, una de cuyas obras fue vertida a telenovela: "Lo que más me motivó a que se llevara Las muertes ajenas a la TV fue el aspecto económico"12.

${ }^{10}$ Galeano, Eduardo. "Defensa de la palabra". Folios, Bogotá, Universidad Pedagógica Nacional, Vol. 1. No. 3, 1980 pp 292-306.

11 "Visor". El único objetivo de nuestra TV es vender". (Entrevista con Rodrigo Beltrán) El Espectador, Bogotá, septiembre 27 de 1987, p 4-B.

12 El Mundo Semanal. "Literatos en telenovela" (resumen de las entrevistas realizadas para El Mundo por Beatriz Mesa), Medellín, Julio 11 de 1987, p. 2. 
Por los mismos días leía que el teleautor argentino Juan Carlos Gené, tan de moda hoy en nuestro medio, declaraba que no ve telenovelas y que el género le parece "horrible". Como iniciando una nueva moda, la de hablar mal de la gallina de los huevos de oro.

Álvarez G., guionista e inspirador de tantas versiones, es más declarativo. Manifestó, en defensa de su ocupación, que:

"Haciendo estos libretos no hago sino gozar, porque esto, ni plata da"13.

Con todo, poco tiem po después, declaró:

la experiencia fue ingrata con El Divino en televisión porque no hubo respeto moral... Y lo peor es que se amparan en que pagan bien ${ }^{14}$.

¿En qué quedamos? Durante la citada entrevista para la revista Pluma, él mismo llegó al fondo del dilema:

Yo lo que estoy haciendo es volviendo El Divino asequible a la filosofía de una programadora, con todos sus caprichos, exigencias, necedades y limitaciones, a la filosofía del sistema que nos rige, democrático o no, pero que obliga a guardar un respeto por las señoras de Medellín o por los peluqueros de Colombia (...) Si prostituirse es gozar, pues prostituyámonos, que yo estoy gozando al escribir esta telenovela ${ }^{15}$

Al fin y al cabo, entendámonos, así son los negocios. Lo reforzaba Pepe Sánchez, director de las "Dinastías" colombianas, cuando, en un reportaje para El Tiempo, frente al hecho de que protes tó contra las series norteamericanas, y pillado en su pertenencia al mismo medio, se absolvió con la simple observación de que "el que peca y reza, empata" ${ }^{16}$. Pues bien; en un apunte titulado "Literatura y prostitución", el novelis ta argentino Ernes to Sábato sintetizó esta paradoja:

¿Cómo vivir?. De cualquier modo que la creación no sea manoseada, bastardeada, abaratada: poniendo un tallercito mecánico, trabajando en un banco, vendiendo baratijas en la calle, asaltando un banco ${ }^{17}$.

Tal es el dilema para el escritor colombiano de estos tiempos. O mantenemos, por encima de las dificultades, del desconocimiento, de la pobreza material, la dignidad de nuestro oficio, o caemos en brazos de la mediocridad que estimula la

\footnotetext{
${ }^{13}$ Revista Pluma ed. cit.

${ }_{14}^{14}$ El Mundo Semanal, ed. cit.

${ }^{15}$ Revista Pluma, ed. cit.

${ }^{16}$ Neira, Armando. "Pepe Sánchez se confiesa: la T.V. es una feria" (Entrevista) Lecturas Dominicales de El Tiempo. Bogotá, septiembre 27 de 1987 p. 8

${ }^{17}$ Op. Cit. p. 165.
} 
peor tradición nacional y dejamos que el ánimo de lucro, imperante gracias a la acelerada descomposición, compre también nues tras conciencias.

\section{“Capitalización del espíritu”}

La verdad, el fenómeno no es nuevo. Lo puso al descubierto, ya en el siglo XVIII, Diderot en El sobrino de Rameau ${ }^{18}$, y en el XIX constituyó el asunto de varias obras de los clásicos de la novela, como Stendhal y Zolá. Marx lo describió, en su minuciosa observación de la época, y consignó la situación de asalariado del escritor con respecto a los editores, el carácter de mercancía de los libros, la hostilidad del sistema capitalista frente al $a^{2}{ }^{19}$. Además, en sus lúcidos artículos sobre la censura ${ }^{20}$ presisó:

El escritor, por cierto, debe tener la posibilidad de ganarse la vida para poder existir y escribir, pero en modo alguno debe existir y escribir para ganarse la vida (...) El escritor no considera de ninguna manera su trabajo como un medio. Es un objetivo en sí; hasta tal punto (...) que brinda en sacrificio la ofrenda del trabajo y, cuando hace falta, su propia existencia pers onal.

Años antes, Kant hablaba de un "arte libre" contrapuesto a uno "mercenario" y caracterizaba al segundo como "ocupación en sí misma desagradable y que sólo es atractiva por su efecto (vgr, ganancia)" ${ }^{21}$. Es lo que ocurre con la pintura y su intrincada red de intemediarios, galerías, promotores, "marchantes", etc., o con la música, en particular con expresiones populares, llámense jazz, salsa, vallenato... La comercialización consagra o veta, condena, impone pautas de difusión o destina al silencio, acaba o crea efímeros prestigios.

Tal situación hace forzosa la evocación de la magistral novela de Honorato de Balzac, Ilusiones perdidas ${ }^{22}$. Esta obra configura la más brillante reflexión sobre este drama de la literatura. Cuenta cómo el joven provinciano Lucien Chardon, poeta de su poblacho, Angouleme, viaja a la capital, París, en procura de "la gloria, el poder y el dinero". Una vez en la ciudad, su devoción poética resulta ingenua para las "madames' y "mademoiselles" que se prendan de su apariencia física pero se sienten defraudadas por su obstinación literaria. Con el fin de corregir una novela, Lucien entra en contacto con un grupo de escritores tan desamparados como él, pero que mantienen una erguida fidelidad a su vocación artística; los dirige Daniel D'Arthez (un poco el vocero del propio Balzac). Lucien, quien cambia su "vulgar" apellido por el de la familia de su madre (Rubempré), y lo

\footnotetext{
${ }_{18}^{18}$ De Diderot, Denis, Le neveu de Rameau. París, Eds. du Seuil, 1968.

${ }^{19}$ Marx, Karl. Historia crítica de la teoría de la plusvalía. Buenos Aires. ed. Cartago. 1956, tomo IV.

${ }^{20}$ Marx, Karl, y Federico Engels. Sobre arte y literatura. Madrid. Ciencia Nueva, 1968 p. 131.

${ }^{21}$ Kant, Emmanuel. Crítica del juicio, Buenos Aires.: Librería El Ateneo, 1961. p 312.

22 De Balzac. Honoré. Illusions perdues. (3 vols). Géneve: Les Editions du Cheval Ailé, 1945.

(Todas las citas de Balzac se refieren a esta obra).
} 
hace preceder de un ostentoso "De", escucha con la boca abierta a D'Arthez y sus cofrades. Al mismo tiem po constata que para los libreros, "Ios libros son como los sombreros para los sombrereros: una mercancía que se compra barata y se ven de cara". Y capta que, como lo señala una estudiosa colombiana:

El público pedía novelas, y sobre todo, novelas entretenidas, apasionantes y poco profundas, como las que habían puesto en circulación los periódicos en sus famosos "folletines" 23

No obstante las advertencias de sus compañeros del Cénacle de D'Arthez, Lucien de Rubempré cae en manos de un escritor corrupto, Lousteau, quien lo vincula al mundo de los periódicos (por entonces tan decisivos entre la "opinión pública" como lo es hoy la televisión), y hace que se embrolle en el turbio medio del negocio literario, de la carencia de principios, del lucro a través de la pluma, del "almacén donde se vende al público palabras del color que és te las desee".

Arribado a su nuevo status, Lucien conquista a la actriz de teatro que lo desvelaba y alcanza una pasajera popularidad, amén de ropa elegante, un buen lugar donde vivir y dinero para satisfacer sus antojos. Súbitamente la suerte cambia, como suele suceder. La miseria física, entonces, se convierte en miseria moral. Lucien termina en el más oprobioso enlodamiento, y su triste final está narrado por Balzac en las páginas de Esplendores y miserias de las cortesanas, donde el maes tro del realismo francés cierra el círculo de esta y otras historias.

En un agudo anális is de Ilusiones perdidas, Georg Lukacs ${ }^{24}$ explica cómo "Balzac muestra allí el proceso de formación del capitalismo en el campo del espíritu". Precis amente por ello, no puede producir cosa distinta de lo que el crítico húngaro llama la "novela de la desilusión".

Contem poráneamente, Sábato coincide:

Si nos llega dinero por nuestra obra, está bien. Pero escribir para ganar dinero es una abominación. Esa abominación se paga con el abominable producto que así se engendra ${ }^{25}$.

El añejo ejemplo de Balzac, como los de Diderot, Marx o Kant, nos ganarán el epíteto de "decimonónicos". Sánchez Juliao dijo:

Si hablamos de comercialización y de prostitución al amparo de la lente decimonónica, pues hombre, escribir directamente para televisión, como lo hice yo con Gallito Ramírez, puede tildarse aún más de comercialización.

\footnotetext{
${ }^{23}$ Casas Dupuy, Rosario. "Balzac y el problema de la "capitalización de la literatura". Cuadernos de Filosofía y Letras. Bogotá, Universidad de los Andes Vol 2, No. 51979. pp. 167-181.

${ }^{24}$ Lukacs, Georg "Balzac: Ilusiones perdidas" Ensayos sobre el realismo. Buenos Aires, Siglo XX. 1965, pp 65-86.

${ }^{25}$ op. cit. p. 86
} 
Yeso que, en la misma mesa redonda, opino:

Yo creo que sí, que de pronto este género toca, de alguna manera, los linderos del costumbrismo ${ }^{26}$.

Como es sabido, el costumbrismo imperó en América Latina en el siglo XIX y sólo la superación de tal estilo permitió el surgimiento de la novelística en nuestras tierras.

Entrevistado en el mismo momento, el alcalde de Tuluá emitió dos conceptos que vienen a ser útiles para la confrontación: por una parte, se puso moderno:

El trabajo de prender un televisor es simplemente hundir un botón. Ahí ya hay una diferencia. No nos podemos quedar con los métodos decimonónicos.

Por otro lado, fue evocador:

Me siento un Tomás Carrasquilla es cribiendo La Marquesa de Yolombó por entregas y publicándola cada ocho días en un periódico de Medellín. Es lo mismo que estaba sucediendo a fines del siglo pasado (...) y aquí lo que se está montando en las telenovelas es más o menos eso, es una continuación de una viejísima tradición colombiana ${ }^{27}$.

Una vez más, señores: ¿en qué quedamos? la respuesta señala el lucro. Resulta, pues, pertinente recordar al más profundo poeta de las nuevas generaciones colombianas, Juan Manuel Roca, cuando en su "Flor de Ocio" parecería definillos:

Yo los veo. Afanados. Llenando las horas de palabras

Que entrecruzan para ver cómo brota el fruto del negocio, $Y$ negocio, negar el ocio, Es la mágica palabra que convocan ${ }^{28}$.

\section{De la pantalla chica}

Desde cuando la radio transmitió en Colombia El derecho de nacer, de Félix B. Caignet, el género no ha variado su esquema sensiblero, enajenador y barato. El mismo que diseñaron los infortunios de Albertico Limonta. Aquel novelón, sin embargo, era franco; hoy se disfraza la opereta con un ropaje semiológico, con "teorías" acerca de la "verdadera cultura popular", de la "actuación natural" o de "la peculiaridad de los medios".

\footnotetext{
${ }^{26}$ Revista Pluma, cit.

27 Ibid.

${ }^{28}$ Roca, Juan Manuel "Flor de ocio". En Antología poética. Félix Burgos Editor, Bogotá.1983, p.171.
} 
¿Por qué habrá sido olvidada la clarísima conclusión de uno de los mejores críticos colombianos, Baldomero Sanín Cano? El maestro decía:

La ola romántica trajo entre nosotros la boga del cuadro de costumbres. Se abusó del género porque su aparente facilidad convidaba a los escritores inexpertos. Abundaron las colecciones de artículos de costumbres y en las revistas semanales era la cosecha más copiosa. La popularidad de muchos años vino a parar en el descrédito de mucho tiempo.

En el fondo, la cuestión es con dinero. La magia de ese "Poderoso caballero" invierte cualquier valor, por respetable que sea.

Limitemos los ejemplos al caso colombiano. No hace mucho tiempo, alguna programadora tomó la iniciativa de adaptar la novela La canción del verdugo, de Norman Mailer; una primera versión, del periodista Javier Darío Restrepo, fue descartada por los productores en virtud de que la consideraban "irrealizable". O sea, bien hecha, con exigencias, con necesidad de inversión. Apelaron entonces a una burda deformación del texto. La revista Semana, en su resumen de la polémica que tal atropello generó, consignó diversas opiniones ${ }^{29}$, entre otras las del director, Alí Humar, y las del actor protagonista, Santiago García, conocido animador de un grupo teatral. Este último argumentó:

Yo acepté el papel porque se trata de una versión, o sea una propuesta que parte de la novela pero que no se somete a ella. (...) Aquí queremos hacer una cosa más original, puede que no sea tan buena como la novela de Mailer, obvio, una novela tan importante, best-seller en los Estados Unidos; aquí nos limitamos a las posibilidades que tiene nuestro medio y a que el público masivo pueda encontrar una cierta verosimilitud en esto que se le está narrando.

Ahí se define un tipo de teatro colombiano, "más original" que la buena producción artística, "que no se somete" a la cultura universal, venerador de los "best-seller", conforme con "nuestro medio" y con el "público masivo", presuntamente condicionado por "una cierta verosimilitud". Todo este disfraz pseudoteórico fue desnudado por un anónimo lector de la revista que, en la misma encuesta, dijo: "Esto no es una versión; es una perversión".

Tal cual opera todo el andamiaje del "medio". Con el único propósito de ganar más y más dinero, se alarga la trama, o se la acorta sin piedad; se "mata" un personaje porque el actor llega tarde al ensayo, o bien se minimiza o maximiza el peso de galanes o heroínas, según varíen las contingencias picantes que caracterizan la vida de "la farándula".

Abundantes historias de celos, intrigas, envidia y ambiciones rodean la intimidad de actores, directores, productores y técnicos; en el panorama palidecen las

${ }^{29}$ García, Santiago. Entrevista para Semana “¿Verdugos de una novela?” 
propias telenovelas. Y hasta los autores se "pachanguean" en la TV, como tituló para la ocasión Cromos, vendiéndoles un mismo esbozo de guión a dos diferentes programadoras.

Ahora bien, si la fómula vendedora es aludir a un determinado tipo de música, surgen decenas de guiones apoyados en la ranchera, el bolero, el joropo, el vallenato... Para un mayor éxito, mézclese con la burda imitación de acentos regionales, pues ahí están a la mano costeños, paisas, vallunos, pastusos, rolos, llaneros... Los más ridículos extremos se nos presentan como una "crítica" del género, y hasta surgen académicos defensores de cualquier tosca producción como "lo auténticamente nacional" o "lo que de veras gusta al común de las gentes" e incluso como "la cultura popular".

Quienes así opinan reconocen su incapacidad para producir algo profundo y trascendente. El nivel general de los dramatizados colombianos no admite comparación con el de los brasileños, por ejemplo, ni en su trama, ni en la actuación, ni en la producción. Para no hablar de lo que puede verse en otros países del Tercer Mundo, con un efecto educativo acerca de variados aspectos de la vida social ${ }^{30}$.

\section{¿Actores? ¿Escritores?}

Parecería superfluo hablar de las actuaciones, en sus grandes mayorías deplorables, improvisadas, faltas de profesionalismo. Sin embargo, en no pocos medios de nuestra sociedad estas se han convertido en modelos, pautas de criterio, referencia obligada para la formación de un gusto acerca del oficio del actor. Corrupción del gusto, debería decirse.

Alguna vez, en Semana, Martha Bossio comparo una telenovela brasileña con una venezolana. Hablando de los actores, señalaba: "Mientras Sonia Braga sólo es reconocida con admiración entre los círculos cinematográficos que han visto sus películas, El Puma es un ídolo popular que vende discos como pan". He ahí el criterio que se aplica para elegir a los protagonistas de las telenovelas. No se busca contar con actores, no se estimula el profesionalismo. Para el negocio es mucho más importante la popularidad.

Así, es natural que las reinas de belleza, las virreinas y princesas, los condes de las discotecas y los marqueses de la carrera quince de Bogotá se hayan convertido en "actrices" y "actores", amparados por la sofística teoría de la "actuación natural".

En realidad, nadie habla como lo hacen ellos en sus interpretaciones, en las cuales muestran una única seguridad: la que tienen frente al texto, pues los apoya el "apuntador electrónico". De tal modo, el tipo de televisión que se realiza en

\footnotetext{
${ }^{30}$ El fenómeno es estudiado por Rogers Everett M. Y Livia Antola en "Telenovelas" A Latin American Success Story", Journal of Communication Philadelphia University of Pennsylvania Vol $35,4,1986,24-35$.
} 
Colombia ha deformado la carrera de un puñado de jóvenes, algunos talentosos, y prostituye la formación de estudiantes de las escuelas de actuación.

Para Sánchez Juliao, el aporte cultural es la "burla del género" y la "exaltación de la identidad regional" 31 . Homóloga opinión tiene el cantante venezolano Carlos Mata, en una entrevista titulada "No soy una sanguijuela":

La novela rosa es parte de la cultura del pueblo. (...) Sabemos que tenemos el poder de influir sobre las personas que nos ven. En Cristal, por ejemplo, se trató el tema del alcoholismo y del cáncer del seno en la mujer. Ofrecimos una ayuda terapéutica al público ${ }^{32}$.

Más franca y objetiva, Lucía Méndez confes aba sin rubor:

Si uno quiere aplicarles una medida intelectual, si quiere mirarlas como elementos culturales, que sirvan para mejorar los conocimientos, se sentirá defraudado, porque las telenovelas, nosotros los que hacernos telenovelas somos conscientes de ello, apenas sirven para divertir al pueblo, para entretenerlo. (...) La gente mirando telenovelas se olvida de la realidad que los rodea, se escapan, es cierto, se proyectan en los personajes y las historias lindas que miran en la televisión, se sienten como esos hombres hermosos que seducen muchachas lindas y viven en casas rodeadas de fuentes y jardines ${ }^{33}$.

Pero tal no es sólo el criterio de actrices vedettes; directores y libretistas comparten el mismo espíritu, siempre bajo la presión de ahorrar y producir dividendos. Generalmente, los actores disponen apenas de minutos para el estudio de sus personajes. Lo confima Frank Ramírez, quien alguna vez decidió "no hacer más televisión" argumentando:

"Esto del tiempo se observa en cualquiera de los trabajos que uno ve en la televisión colombiana; uno se topa con actores tratando de perseguir un texto y no un personaje, preocupados para que no los maten el director y la programadora si se toman más tiempo del acordado. La televisión colombiana es un suicidio... Es suicida para el actor ${ }^{34}$.

Los libretistas, por su parte, no son menos elocuentes. Para Sánchez J., por ejemplo:

\footnotetext{
${ }^{31}$ Revista Pluma, ed. cit.

32 Bellon, Manolo "No soy una Sanguijuela" (Entrevista con Carlos Mata) El Tiempo. Bogotá, Agosto 22 de 1987, p. 3 F.

${ }^{33}$ Entrevista de la revista Semana a Lucía Méndez.

34 "La TV œlombiana, suicidio para el actor". Dedaraciones de Frank Ramírez para Semana.
} 
Un guión para televisión (...) no exige la pulcritud literaria y el trabajo artesanal que exigiría un texto para ser publicado (...) De tal modo que es una manera relativamente fácil de ganarse unos pesos ${ }^{35}$.

En verdad esto es comprensible; especialmente si tenemos en cuenta que, en palabras de la revista Semana, este mismo guionista, en alguna ocasión

entregó originalmente a la programadora un cuento corto (...) de donde debía surgir el argumento (...) Se pensó en un comienzo en una serie corta, que no pasara de 40 capítulos. Pero ante el éxito del "Gallito", la serie fue alargándose por solicitud de la programadora a la libretista, hasta llegar a 148 capítulos $^{36}$.

La aludida libretista no era otra que Martha Bossio de Martínez, por cierto escogida por Gabriel García Márquez como su monitora en un curso para mujeres latinoamericanas guionis tas de televisión que dictó en La Habana. Con respecto a la misma producción, doña Martha ofreció atafagadas explicaciones en su momento:

Si entrego tarde los libretos, es por miles de motivos. Todos nos montamos tarde en el avión de Gallito Ramírez ${ }^{37}$

Por su parte, el autor de El divino consignaba:

Hacer libretos de televisión (...) obliga a limitarse en muchísimos niveles, de tiempo de producción, de censura. (...) Hago treinta páginas de un libreto en tres horas y media. No tengo problemas en esto ${ }^{38}$.

Actores inventados, improvisación de los libretos, directores hechizos, presión de las programadoras, imperio del negocio. No puede sorprender, entonces, la mediocridad de nuestra televisión.

\section{¿Y de la literatura...qué?}

Las consecuencias de esta moda afectan el proceso de la narrativa colombiana de manera grave. Algunos escritores han caído en la tentación y pemitieron que sus textos fuesen destrozados; otros se dieron con entusiasmo al lucro que representa la televisión; gana terreno la preocupante actitud de (luienes escriben porque "buscan fama y dinero, por distracción, (...) por que no resisten la vanidad de ver su nombre en letras de molde" ${ }^{39}$.

\footnotetext{
${ }^{35}$ Revista Pluma, Ed. cit.

${ }^{36}$ En Semana, Bogotá, febrero 24 de 1987, p. 47.

${ }^{37}$ Dedaraciones para Semana febrero 24 tic 1987, p. 47

${ }^{38}$ Revista Pluma, ed. cit.

${ }^{39}$ Sábato, op. cit. p. 84.
} 
En varios casos, por esta causa, se ha retrocedido en más de un siglo hacia el costumbrismo. En otros, se cede ante lo más instintivo y atrasado del "públicomasa" del cual habla Sábato. No solamente en el resultado que presenta la "pantalla chica"; también en los muy vendidos libros que el "medio" promueve. Las novelas de Alvarez G. y Sánchez J. no resisten un anális is literario serio. Ninguna de ellas representa un aporte a nuestra novelística, ni en lo referente a los temas, ni en materia de técnica narrativa, ni por lo que respecta a la incorporación de la música al relato, ni mucho menos en cuanto al tratamiento del lenguaje. Ni hablar del escaso interés social o psicológico de sus ambientes y personajes.

Pero son tales productos, inocuos, perecederos y prescindibles, los que se establecen como modelos para buena parte de los editores. A los más jóve•nes narradores se les constriñe a "escribir como para la adaptación", el llamativo negocio. Los libros se promueven con el señuelo de que "muestran lo que no se puede pasar por la pantalla". Crece así esta truculenta feria de las vanidades; como en la citada novela de Balzac, "Es difícil tener ilusiones sobre alguna cosa en París. Aquí hay impuestos sobre todo, se vende todo, se fabrica todo, hasta el éxito" ${ }^{40}$.

La más repugnante manipulación, en medio de esta capitalización de la literatura, es la que se ejerce sobre la conciencia cultural de la sociedad, de ese "pueblo' al que se pone como escudo porque "hay que darle gusto". La mayoría de los escritores que incursionaron en la aventura del pantallazo manifestaron su descontento a la periodista Beatriz Mesa de El Mundo de Medellín ${ }^{41}$. Cada uno, desde su punto de vista, expresó decepción. Examinemos algunas declaraciones:

Ketty Cuello de Lizarazo (San Tropel); Me di cuenta de lo que iban a hacer y no puedo negar que me golpeó.

Era de esperarse; la adaptadora, señora Bossio de Martínez, dijo al respecto:

Inicialmente se había pensado en Miguel Varoni para personificar a Mauricio. Cuando el contrato con él no se realizó y Bernardo (Romero Pereiro) escogió para el papel a un joven sin experiencia actoral, yo me vi obligada a modificar sus características. (...) Constanza era un personaje muy blanco y yo necesitaba darle una personalidad más recia, introducirle conflictos, volverla atormentada y crearle problemas. En el libro no existía ese requerimiento pues sólo eran 150 páginas ${ }^{42}$.

Los demás entrevistados en el citado trabajo de Beatriz Mesa dijeron, por ejemplo:

\footnotetext{
40 Balzac, op. cit.

41 El Mundo, ed. cit.

42 En Elenco de El Tiempo. Bogotá, febrero 4 de 1988, No. 429, p. 14 (Todas las citas de esta revista se refieren a la misma edición).
} 
Juan Gossain (La mala hierba, El huracán); Yo creo que la TV, por la rapidez, no es apropiada para la literatura.

Germán Castro Caycedo (Mi alma se la dejo al diablo): Es demasiado triste trabajar en un libro para que se lo quemen a uno. No se mata así a un hijo.

Juan José Hoyos (Tuyo es mi corazon): Estropean las mejores historias para volverlas artificiosas y son capaces de prostituir al personaje más lindo, para ganar dinero

Hasta los comentaristas de la farándula se percatan de estas deformaciones. En el balance de San Tropel ya traído a cuento con las declaraciones de su adaptadora, Ana Sofía Sierra, de El Espacio, reprochó el 'esquema reiterativo", 'la fórmula del éxito", y Germán Yances, de El Espectador, conceptuó acerca de la "calidad muy regular del reparto" de una telenovela vacía de contenido" y del hecho más grave: "Martha Bossio le quitó al libro la crítica social y lo convirtió en un anecdotario. Mutiló la obra".

En la misma encuesta hubo otros observadores condescendientes, como Santiago Coronado, de El Tiempo: "Si bien trabaja elementos del melodrama, ha sabido percibir dimensiones culturales nuestras sin caer en el costumbrismo"; hubo un "trabajo interesante" de los actores; $y$ "dio un mensaje de alegría al televidente que se enfrenta diariamente a un alto porcentaje de contenidos violentos".

Idénticas justificaciones fomulaba el director Jorge Alí Triana:

En materia de televisión, encuentro las telenovelas colombianas mucho más interesantes que las venezolanas. Las nuestras tocan elementos de la cultura popular que las diferencian del folletín de novela rosa venezolana y mexicana ${ }^{43}$.

O, como diría Sánchez Juliao, "abrir un paréntesis, ya sea para ejercer la política o para ejercer la televisión, es respetable ${ }^{44}$.

Y en defensa de los telefolletines se alzan otras voces. Académicos para los cuales se trata de "la más auténtica expresión nacional", "lo que podemos hacer con nuestros recursos", "una inteligente apertura hacia el consumo masivo". Cuando surgen reparos a los productos de su comercio, se argumenta, como algún articulis ta, que la crítica proviene de "un sector intelectual" que todo lo quiere "tremendamente complicado para que parezca tremendamente inteligente", mientras que el arte "es simple"45. ¡Y vaya si son simples los niños y papás,

\footnotetext{
${ }^{43}$ Triana, art. cit.

${ }^{44}$ Revista Pluma, ed. cit.

45 "Por fin una" (Sobre la película El embajador de la India) Semana. Bogotá No. 258. 1987, pp. 58-
} 59. 
divinos, gallitos, sangres plebeyas, tropeles y caballos viejos! Cabe preguntarse, con Baudelaire:

¿Qué hombre, digno del nombre del artista, qué genuino amante del arte ha confundido nunca la industria con el arte? ${ }^{46}$.

Porque no parece haber motivación distinta de la económica para la ola de "telenovelitis". Con alguna resonancia familiar, Balzac subrayaba en ilusiones Perdidas que la "veneración del becerro de oro se produce en todas las imaginaciones provincianas como un Eldorado". En el ámbito latinoamericano, Eduardo Galeano deslindó el campo. A propósito de la mal llamada "cultura de masas", observó:

Cultura para masas, debería decirse, definición más adecuada para ese arte degradado de circulación masiva que manipula las conciencias, oculta la realidad y aplasta la imaginación creadora. No sirve, por cierto, a la revelación de la identidad, sino que es un medio de borrarla o deformarla, para imponer modos de vida y pautas de consumo que se difunden masivamente a través de los medios de comunicación ${ }^{47}$.

Por fortuna, a pesar de que pareciera imponerse la tendencia a la persecución de la fama, al lucro y al facilismo, la tentación de los mercaderes no ha afectado a los escritores que persisten con rigor en su arte, ajenos a la autopromoción y la vanidad. Ellos no venden tantos ejemplares de sus obras como los televisados, pero sí producen novelas que contribuyen al desarrollo de nuestra historia cultural y conquistan, lenta pero firmemente, un público nuevo, el de los lectores exigentes que, en medio de la maraña de prestigios fabricados por la publicidad, han aprendido a distinguir los aciertos y a valorar el trabajo y el talento ${ }^{48}$.

Así mismo, contadas pero día a día mejor apreciadas realizaciones cinematográficas logran escapar a la complacencia imperante, y justamente son las que han sido llevadas a cabo con esfuerzo, seriedad, conciencia profesional, paciencia y respeto por el arte ${ }^{49}$.

\section{Algo de crítica}

${ }^{46}$ Citado por Erie J. Hobshawm en La era del capitalismo, Madrid, Guadarrama, 1977. vol 2 p. 182.

${ }^{47}$ Galeano, art. Cit.

${ }^{48}$ Con el peligro de exduirinvoluntariamente a narradores importantes, mencionemos al menos los nombres de Luis Fayad, Rafael Humberto Moreno Durán, Rodrigo Parra Sandoval, Alfonso Aristizúhal, Policarpo Varón, Roberto Burgos Cantor, Darío Ruiz. Gómez, Fernando Cruz Kronfly, Germán Espinosa, Humberto Valverde.

${ }^{49}$ Pienso, por ejemplo, en la realización cinematográfica de Tiempo de Moriro en la de Cóndores no entierran todos los días, película que superó con mucho el "original” novelístico. 
Ocurre con frecuencia que los escritores de nuestro medio se quejan 'de una supuesta ausencia de crítica literaria; la verdad es que quienes la ejercen son los que logran una menor audiencia entre sus contem poráneos, y que en Colombia el ejercicio de criterio choca con la autoestima de numerosos autores y con la señalada tradición del mutuo elogio. Pero la crítica existe. Se lleva a cabo en las universidades un atento análisis de la producción literaria nacional. Si esto sólo llega a unos cuantos estudiantes especializados, y eso por medio de revistas institucionales o independientes de mísera circulación, la responsabilidad no cabe a sus autores, sino a la indiferencia de los medios de comunicación, a la velada censura que han consagrado, a la casi nula recepción de los propios medios intelectuales frente al género.

Naturalmente, tal situación brinda ocasión para las disculpas. Sánchez Juliao, a manera de ejemplo, ripostó ante la observación de que su obra era eminentemente comercial:

Eso lo dicen cinco escritores frustrados. (...) Censuran la forma como me gano la vida, les parece abominable (...) El 50 por ciento de los miembros de la UNE no han publicado un solo libro ${ }^{50}$.

Otro defensor de los telenovelistas, Roberto Montes Mathieu, aprovechó el vigésimo aniversario de la aparición de Cien años de soledad y algunas barbaridades al respecto de los comentaristas de la época, para denostar de un presunto "centralismo crítico" y atribuir al endémico mal colombiano de la envidia las objeciones al negocio de moda en la literatura. Apuntó Montes:

Hija de la deficiencia y la frustración, la envidia es común entre los escritores que se resisten a aceptar que otros han logrado lo que ellos no han podido; por eso a Gustavo Alvarez Gardeazábal y a David Sánchez Juliao no les perdonan que habiéndose iniciado en las letras hace menos de 20 años, sin lazarillos ni permisos, se hayan convertido en dos escritores reconocidos, con obras publicadas y numeros os lectores ${ }^{51}$.

Una vez más, el entero son las ediciones y los ejemplares vendidos en el mercado. Pero Baudelaire no vendía, Joyce fue rechazado, lo mejor de Vallejo solo apareció tras de su muerte, el Tuerto López era un desconocido... Frente a muchos rápidos prestigios, a menudo seguidos de una posteridad certeramente olvidadiza, aquellos verdaderos artistas en ocasiones desconocidos por sus contem poráneos conquistaron una indus cutible memoria en el futuro.

\footnotetext{
${ }^{50}$ Uribe, Carlos. "Censuran cómo mc gano la vida" (Entrevista con David Sánchez Juliao). Lecturas Dominicales de El Tiempo. Bogotá.

${ }^{51}$ Montes Mathieu, Roberto. "Pifias de la crítica: veinte años de Cien años de soledad" Lecturas Dominicales de El Tiempo, Bogotá, mayo 24 de 1987, pp. 6-7.
} 
Y la crítica colombiana no ha sido ingenua ni indiferente a la producción comercial de novelas. Baste citar un par de ejemplos, como el del profesor Gemán López Velásquez, de Pereira, quien sostuvo, entre otras cosas, que en El divino "se palpa ignorancia y, algo más grave, ligereza, como si de publicar para vender se tratara" ${ }^{2}$. Otro docente universitario, Eduardo Jaramillo, es cribió a propósito de Mi sangre aunque plebeya:

Su problemática, si la tiene, es una problemática de revista femenina, complaciente e ilusoria. El único argumento que puede aducirse en defensa de la novela es que su narrador resulta tan lobo y superficial como los demás personajes $\mathrm{y}$, por tanto, la frivolidad tic las páginas que escribe es la condición tic su verosimilitud ${ }^{53}$.

En fin de cuentas, pues, cabe aún el optimismo frente al desarrollo de la narrativa en nuestro país. Como el que manifestaba José María Arguedas a nivel continental, cuando expresó:

Todo eso es para ganar plata. ¿Y cuando ya no haya la imprescindible urgencia de ganar plata? Se desmariconizará lo mariconizado por el comercio, también en la literatura, en la medicina, en la música, hasta en el modo como la mujer se acerca al macho ${ }^{54}$.

\footnotetext{
52 López Velásquez, Gemán. "Gardeazábal y la cocaína literaria' La Tarde, (Dominical) Pereira, marzo 29 de 1987, pp. 4-6;

53 Jaramillo, Eduardo "Lobelas para bobos" Boletín Cultural y Biblioráfico, (Biblioteca Luis Ángel Arango). Bogotá, Vol XXIV, N II, 1987, p. 121.

${ }^{54}$ Arguedas, José María, El zorro de arriba y el zorro de abajo. Buenos Aires, Losada, 1971, p. 19.
} 